\title{
Developing an index for heavy convective rainfall forecasting over a Mediterranean coastal area
}

\author{
M. Korologou ${ }^{1}$, H. Flocas ${ }^{2}$, and H. Michalopoulou ${ }^{2}$ \\ ${ }^{1}$ Hellenic National Meteorological Service, Athens, Greece \\ ${ }^{2}$ National and Kapodistrian University of Athens, Faculty of Physics, Department of Environmental Physics-Meteorology, \\ Athens, Greece \\ Correspondence to: M. Korologou (marina.korologou@gmail.com)
}

Received: 13 December 2013 - Published in Nat. Hazards Earth Syst. Sci. Discuss.: 25 February 2014

Revised: 7 January 2014 - Accepted: 12 July 2014 - Published: 27 August 2014

\begin{abstract}
Heavy convective rainfall incidents that occurred over western coastal Greece and led to flash floods are analyzed with respect to mesoscale analysis for the period from January 2006 to June 2011. The synoptic scale circulation is examined throughout the troposphere along with satellite images, lightning data and synoptic observations of weather stations. Well-known instability indices are calculated and tested against synoptic observations. Taking into account the severity of the incidents, the performance of the indices was not as good as expected. Further detailed analysis resulted in the development of a new index that incorporates formalized experience of local weather and modeled knowledge of mechanisms of severe thunderstorms. The proposed index named Local Instability Index (LII), is then evaluated and its performance is found to be quite satisfactory.
\end{abstract}

\section{Introduction}

Thunderstorms accompanied by heavy rainfall often lead to flash flood events with disastrous consequences on the economy, the environment and, in some cases, have resulted in fatalities. Although the performance of the numerical weather prediction models have been improved (Kelley and Källén, 2013), further study is always challenging due to their impacts.

One of the fundamental conditions for a thunderstorm initiation is the existence of an unstable atmosphere. In order to estimate the instability, thermodynamic indices have been created by combining related meteorological parameters (Showalter, 1953; George, 1960; Boyden, 1963;
Jefferson, 1963a; Jefferson, 1963b; Miller, 1967; Litynska et al., 1976; Peppler, 1988; Peppler and Lamb, 1989; Jacovides and Yonetani, 1990; Reuter and Aktary, 1993; Tian and Fan, 2013). These indices have not always shown satisfactory results due to local effects that are not well represented or due to limited data sets.

Related studies have been carried out for specific regions of Greece with acceptable results (Dalezios and Papamanolis, 1991; Michalopoulou and Karadana, 1996; Sioutas and Flocas, 2003; Chrysoulakis et al., 2006; Marinaki et al., 2006). The main challenge of these studies was the availability and reliability of observation data, as the existing radiosonde network is rather insufficient. It has been shown that the performance of the indices depends on the season or even month, the terrain of the area and the type of the thunderstorms (Michalopoulou and Jacovides, 1987; Prezerakos, 1989; Dalezios and Papamanolis, 1991; Haklander and Van Delden, 2003; Tyagi et al., 2011).

Western Peloponnese, being washed by the Ionian Sea, is an area that is frequently affected by severe thunderstorms (Maheras and Anagnostopoulou, 2003; Metaxas et al., 1999; Ziakopoulos, 2009; Xoplaki, 2002). However, relevant studies have not been performed so far, mainly due to the lack of radiosondes data. The objective of this study is to examine the thermodynamic environment of severe thunderstorms with respect to heavy rainfall occurring in this area for the period of 1 January 2006 to 30 June 2011. An alternative methodological tool for developing a useful and practical index is proposed. This index is going to be used for forecasting these events without employing radiosondes data because 
they are not available for most hydrological basins of magnitude 5 and above.

\section{Data}

The severe thunderstorms with heavy rainfall that occurred in the examined area of northwestern Peloponnese (see Fig. 1), more specifically over the hydrological basin defined by the rivers Peiros, Parapeiros, Vergas and Pinios (almost $2500 \mathrm{~km}^{2}$ ) (MEECC, 2012) during 1 January 2006 to 30 June 2011, were considered. For this purpose, a mesoscale analysis of the atmosphere with a $6 \mathrm{~h}$ time step for that period was performed. Data sets of dry and dew point temperature at the surface and geopotential height, temperature and humidity at the isobaric surfaces of $850,700,500,300 \mathrm{hPa}$ were used. The 6-hourly synoptic scale analysis of the atmosphere derived from the archive of the Hellenic National Meteorological Service (HNMS) and a re-analysis of $0.125^{\circ}$ resolution from the European Centre for Medium-Range Weather Forecasts (ECMWF) with the same time step were also employed (Veremei et al., 2013). Additionally, the surface synoptic observations (SYNOP) derived from the stations of Andravida, Araxos, Pyrgos and Zakynthos (see Fig. 1) were employed and merged into $6 \mathrm{~h}$ intervals in order to be compatible with the aforementioned time step (i.e., 00:00-06:00, 06:00-12:00, 12:00-18:00, 18:00-24:00 UTC).

Missing merged SYNOP were noticed randomly throughout the available data set, mainly during night hours, weekends and public holidays, representing a percentage of 2.8, 3.1, 51.2, 29.2\% for the stations Andravida, Araxos, Pyrgos and Zakynthos, respectively.

For the dry temperature, the missing data were classified into three categories. The first category is characterized by $6 \mathrm{~h}$ intervals at Andravida station with no available observations from the nearby stations. This category consisted of nine cases. For this category, the Group Method of Data Handling (GMDH) algorithm (Acock and Pachepsky, 2000) was employed with dependent variables:

- the temperature at $850 \mathrm{hPa}$ at the time of the missing observation $\left(T_{850_{0}}\right)$

- the $24 \mathrm{~h}$ trend of $T_{850}$ at the specific time related to the same time of the previous and the next day $\left(T_{850_{0}}-\right.$ $T_{850_{-24}}$ and $T_{850_{+24}}-T_{850_{0}}$ )

- the dry temperature at the same time of the next $\left(T_{+24}\right)$ and of the previous day $\left(T_{-24}\right)$

- the $24 \mathrm{~h}$ trend of the next $6 \mathrm{~h}$ dry temperature related to the corresponding hour of the next day $\left(T_{+30}-T_{+6}\right)$

- the $24 \mathrm{~h}$ trend of the previous $6 \mathrm{~h}$ dry temperature related to the corresponding hour of the previous day $\left(T_{-6^{-}}\right.$ $\left.T_{-30}\right)$

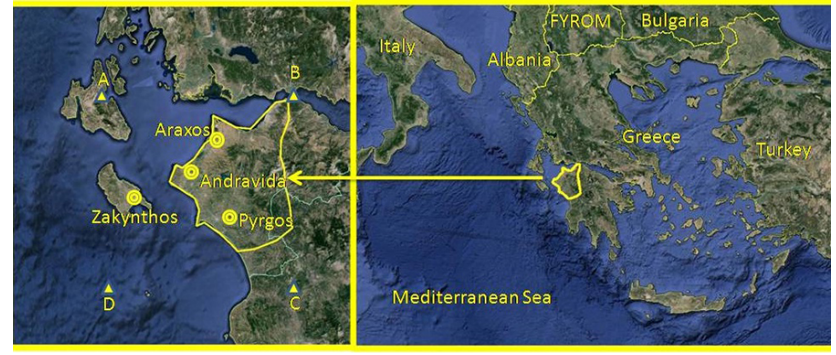

Figure 1. Map of examined area. The locations of the stations are displayed. The points A, B, C, D define the area of lightning data.

- the $6 \mathrm{~h}$ wind runs at the same time, before $24 \mathrm{~h}$ and after $24 \mathrm{~h}$.

The accuracy $\left( \pm 1^{\circ} \mathrm{C}\right)$ was found to be as high as $88 \%$.

The second category consisted of 113 cases, being characterized by available observations at Araxos station at the referring times of the missing observations at Andravida. In this case, the GMDH algorithm was also employed with one more dependent variable, namely the dry temperature of this nearby station. The accuracy $\left( \pm 1^{\circ} \mathrm{C}\right)$ was found up to $90 \%$.

The third category was characterized by 2 or more successive missing observations, consisting of 106 cases. In this case, the GMDH algorithm was not selected, but a qualitative approach was employed instead, with the aid of respective values from the nearby weather stations when available, the synoptic analysis and the satellite images from the satellite Meteosat-9 and more specifically a combination of the SEVIRI High Resolution Visible channel and the IR10.8 channel with the aid of the CineSat application.

For the surface relative humidity, the 228 missing merged observations were filled with the aid of a qualitative approach, due to the nature of this parameter. The subjective estimation was based on succeeding and preceding observations, on observations of the nearby stations, on the synoptic analysis and on Meteosat-9 images (a combination of the SEVIRI IR3.9, IR10.8 and IR12.0 channels).

The amount of precipitation and the duration of each individual thunderstorm led to their intensity determination. If a thunderstorm occurs within a $6 \mathrm{~h}$ interval in at least one of the examined weather stations with intensity greater than $5 \mathrm{~mm} \mathrm{~min}{ }^{-1}$ for at least $5 \mathrm{~min}$, then this interval is defined as a $6 \mathrm{~h}$ interval of severe thunderstorm.

The lightning data were available for the period 1 June 2008 to 30 June 2011, referring to an area defined by the points with coordinates $A\left(38.33^{\circ} \mathrm{N}, 20.60^{\circ} \mathrm{E}\right)$, $B\left(38.33^{\circ} \mathrm{N}, 21.90^{\circ} \mathrm{E}\right), C\left(37.35^{\circ} \mathrm{N}, 21.90^{\circ} \mathrm{E}\right)$ and $D$ $\left(37.35^{\circ} \mathrm{N}, 20.60^{\circ} \mathrm{E}\right)$ (Fig. 1). Correspondingly, $6 \mathrm{~h}$ intervals being characterized by more than 10 strokes/hour, were considered as intervals of severe thunderstorms. These records were merged with the synoptic observations. However, there were cases with recorded strokes without recorded thunderstorms from the synoptic observations. The identification 
of these cases was further verified with the aid of satellite images (Meteosat-9) as derived from the channel combination named Convection RGB (WV6.2-WV7.3, IR3.9IR10.8, NIR1.6 and the VIS0.6 channels).

This analysis showed $5086 \mathrm{~h}$ intervals with thunderstorm events over the examined area, including 143 intervals of severe thunderstorms associated with rainfall intensity greater than $5 \mathrm{~mm} \mathrm{~min}^{-1}$ for at least 5 min duration or with 10 strokes/hour as detailed above. The specific events potentially lead to flash floods. The remaining 365 cases refer either to thunderstorms with no or relatively small amounts of precipitation or thunderstorms associated with frontal activity, and were excluded from the subsequent analysis. The 143 severe cases occurred from May to October and thus our study became restricted to these.

Due to limited availability of lightning data, two distinct sub-periods were used. The first period, from 1 May 2006 to 31 October 2007, is characterized by lack of the lightning data. The second one, from 1 June 2008 to 30 June 2011, is considered of higher reliability due to the availability of lightning data. In the first one, $1386 \mathrm{~h}$ intervals of thunderstorms occurred, including 54 severe thunderstorms. In the second period 370 events of thunderstorms were observed, including 89 severe events.

A set of metadata were aggregated from the first period data, including:

- veering and backing of winds at surface at 850,700 , $500,300 \mathrm{hPa}$

- temperature and humidity for 6,12 and $24 \mathrm{~h}$ trends at surface, $850,700,500,300 \mathrm{hPa}$ (i.e., $\Delta T_{6 \mathrm{~h}}$ etc.)

- surface pressure for 6,12 and $24 \mathrm{~h}$ trends

- geopotential heights trends at $850,700,500,300 \mathrm{hPa}$

- thickness for all combinations of the surface levels at $850,700,500,300 \mathrm{hPa}$

- components that constitute the instability indices KI, HI, TTI and SWEAT (i.e., $(T-\mathrm{Td})_{\text {Levels }}$ or $\sin ($ wind direction $_{500 \mathrm{hPa}}-$ wind direction 850 textrmh $\mathrm{Pa}$ etc.).

\section{Methodology}

Available data made feasible the calculation of the thermodynamic instability indices KI, HI, TTI and SWEAT. Due to the fact that these indices refer to a specific geographical point, the Andravida surface weather station was chosen as representative of the examined area because this station presented the smallest number of missing data. Although these indices are satisfactory in many cases worldwide, the examined area's performance, following the HeVeS (Hellenic Verification Scheme) (Petrou et al., 2009) and the Yule Index (Marinaki et al., 2006), was found to be poor (Dimitrova et al., 2009) and thus of no practical value. This performance could be attributed to the fact that the indices do not take into account the synoptic scale weather patterns nor the local flows. Therefore the development of a new instability index is imperative.

Severe thunderstorms cannot be modeled or, consequently, predicted either analytically or synthetically (Holton, 2004). The proposed indices for predicting thunderstorms can be considered as a tested hypothesis. These tests were performed for a specific period. Consequently, it is always possible for a proposed index to be rejected if it is applied to or tested on a different period unsuccessfully. These validation tests are performed deductively. The proposed index (consisting of the hypothesis) and its application constrains are considered as prerequisite knowledge for prediction of the event; if the predicted event is not manifested, the hypothesis is rejected (Trochim, 2000). From a set of proposed indices, the index that is tested more strictly is preferred. It is rational to accept that if there is an effective index, it will be among those which are robust and hold against criticism and they have been corroborated.

An index is a successfully tested hypothesis that can be developed from experience, literature or theory, or a combination of these (Graham et al., 2010), i.e., combined hypothesis development. The index derives from a rich explicatory theoretical framework (content), and consequently deductive hypothesis, incorporates formalized related experience and has performed successfully through strict validation tests. It can also be conceived as one that captures the important part of the event behavior.

In order to state and support the effectiveness of the new index, using two different sets of data is suggested. The first is for building the hypothesis, that is, to find the patterns and the rules that associate the events with the meteorological parameters for the specific period. The second is for testing and evaluating the hypothesis according to the Modus Tollens rule (Lakatos, 1963). There was a preference to use the first sub-period (1 May 2006 to 31 October 2007) for building the hypothesis and the second sub-period (1 June 2008 to 30 June 2011) for testing and evaluation. The latter subperiod recorded thunderstorms events more accurately than the former, as explained in Sect. 2, and the testing of the proposed index (hypothesis) is more strict.

The factors responsible for forming the index would be inferentially derived from the theoretical and empirical analysis. Data mining and optimization techniques are employed to determine the critical values of these factors and not the factors themselves, since this would led to an index with poor informative content, in other words, relations between the event and parameters with no meteorological meaning.

In this study the attempt was made to automatically extract association rules and patterns between the events and the data and metadata using the software tools MATLAB and ARMADA for MATLAB (ARMADA, 2011). Data mining techniques such as principal components analysis, 
association rules and cluster analysis were applied to data and metadata.

However, no useful result was found, mainly due to the sparseness of the phenomena in question. The aforementioned algorithms, when applied to cases with rare phenomena modeled by high dimensional data with sparse features, such as in this case, lose their effectiveness. In order to overcome this limitation a lot of effort is necessary, however the derived results lack of the required precision for this case (Beyer et al., 1999).

Thus, in this study, using the described methodological tool of combined hypothesis development was preferred. The index will have the form of a threshold function that flags (or not) a warning for an impeded thunderstorm with heavy rainfall. A value of $100 \%$ for the recall of the index can be a major constrain due to the severity of the consequences of the event.

\section{Developing the new Local Instability Index (LII)}

In this section, the factors accounting for the framework of the index development are depicted and briefly presented along with a specific for the examined area synoptic description.

It is well known that a thunderstorm initiation requires the presence of three elements, namely, energy, moisture and a lifting mechanism (Branick, 1993). Using these elements as a guide, a detailed analysis for the factors that were related to thunderstorm events associated with heavy rainfall was conducted.

These mechanisms are closely related with the synoptic scale circulation over the examined area. More specifically, during the period from May to August (5 to 8) polar air masses arrive over Mediterranean Sea and as they have crossed the warm continent of Europe, they have become dry and warm (Xoplaki, 2002). At the same time, the eastern Mediterranean region is affected by tropical dry and warm air masses (Rodwell and Hoskins, 2001; Hoskins, 1996). Thus, heat is transferred from the warm lower atmosphere layers to the upper layers of the sea, causing the temperature of the lower atmosphere to be reduced. These conditions enhance the stability of the atmosphere, often associated with temperature inversion and trapping moisture in the lower layers (from the surface to $3000-5000 \mathrm{ft}$ ), inhibiting conditions of any cyclogenesis or depressions passes.

In late summer and especially during September the polar jet stream is shifted to the south. An atmospheric perturbation may interrupt the equatorial flow of the jet, as part of it usually moves southwards, causing a northwesterly flow. Consequently, cyclonic conditions are created at the lee side of the Alps (Aebischer and Schär, 1998; Kljun et al., 2000) and the geo-dynamic heights are reduced. The southeastern movement of that part of the jet is usually enhanced by the specific conditions. As the jet gets momentum, it moves further to the south, resulting in further reduction of the geopotential heights and cyclonic conditions over the area of boot and northern Sidra Sea (Trigo et al., 2001). As a consequence, southwesterly winds gradually prevail over the southern Ionian Sea (Brody and Nestor, 1980) enriching even the middle layers of the atmosphere with moisture and reversing the temperature inversion that occurs at the low layers. The examined area is affected by such conditions, as the southwestern stream, in conjunction with local orography, accumulates further moisture in the lower atmosphere, while in the meantime the perturbation has moved eastwards, bringing cold and dry air mass in the upper layers. The combination of these conditions can be explosive and cause severe storms.

Throughout September and October (9 to 10) and when a southwesterly flow prevails in the upper atmosphere, orographic clouds and precipitation are caused over the western Peloponnese windward areas. The shift of winds at $850 \mathrm{hPa}$ to the southwestern sector favors the occurrence of thunderstorms, occasionally severe.

The factors of energy, moisture and lifting are considered as the independent variables of a threshold function that constitute the Local Instability Index (LII), requiring a minimum value for the occurrence of severe thunderstorms.

The analysis was carried out every 6 hours and consequently the index provided warning values every 6 hours lasting for the subsequent $12 \mathrm{~h}$. Due to the severity of the phenomena, it is compulsory for the index to predict all or almost all the phenomena (recall $100 \%$ ) and simultaneously maintain a high and practicable precision.

In order to determine the critical values of the parameters, the precision of LII was set up as the objective function which should be maximized. The required parameters were the changing variables of the objective function constrained to rational values. Constrain was also the value of recall, set up to $100 \%$ as was justified in the previous paragraph. For this purpose, the linear programming (LP)-based branch-and-bound algorithm of the optimization toolbox of MATLAB (R2010a), bintprog, was used (Nemhauser and Wolsey, 1988).

\subsection{Energy term}

Instability is a prerequisite for air mass thunderstorms and can be partially indicated by the Convective Available Potential Energy (CAPE) (Moncrieff and Miller, 1976). Although CAPE is referring to synoptic-scale air mass, it has been shown that CAPE can be used for smaller-scale, local weather diagnosis and prediction (Zverev, 1972). CAPE practically defines how strong the updraughts within the thunderstorm potentially are; stronger updraughts result in heavier rainfalls (Wallace and Hobbs, 2006). 


\subsubsection{ACAPE term}

Using only the data that are available to operational forecasters in their daily duties, the energy term was developed in order to approximate the CAPE. An algorithm in MATLAB was built that accepts the dry temperatures $(T)$ and the dew point (Td) as inputs from the weather stations of Andravida, Araxos and Pyrgos and calculates a mean $T$ and Td (Holton, 2004). The lifted condensation level (LCL) was computed and after simulating the wet adiabatic, finally computed what the temperature (Tp) of the surface parcel would have been if it had been raised in the levels of 850, 700, 500 and $300 \mathrm{hPa}$. The Approximated CAPE (ACAPE) is the difference of $\mathrm{Tp}-T$ and refers to the four pressure levels (ACAPE 850, ACAPE $_{700}, \mathrm{ACAPE}_{500}$ and $\mathrm{ACAPE}_{300}$ ).

$\mathrm{ACAPE}_{\text {Level }}=\mathrm{Tp}_{\text {Level }}-T_{\text {Level }}$

It should be noted that there are a lot of cases of severe thunderstorms with low and sometimes negative CAPE (Curry and Webster, 1999).

Moreover, in this specific case, it can be stated that large amounts of negative $\mathrm{ACAPE}_{850}$ are prohibitive for the development of thunderstorms with heavy rainfall (Peppler, 1988). This finding can be modeled by requiring ACAPE $850 \geq-2.5$. At the level of $700 \mathrm{hPa}$, the positive energy ( ACAPE $_{700}>0$ ) is a prerequisite, especially for the summer period when the geopotential heights are higher and more energy is needed for heavy rainfall to form within the thunderstorm (Bol, 2006). A threshold of 1.5 was noticed for the summer period $\left(\mathrm{ACAPE}_{700}>1.5\right)$. For the upper levels, the smaller values of ACAPE show that there is a smaller possibility for thunderstorm development. Thresholds of -2 and -8 were noted for the levels 500 and $300 \mathrm{hPa}$, respectively $\left(\mathrm{ACAPE}_{500}>-2\right.$, $\mathrm{ACAPE}_{300}>-8$ ).

\subsubsection{Thickness term}

The thermal properties of the 850 to $500 \mathrm{hPa}$ atmospheric layer are often better represented by the thickness rather than the temperature at a single level (Wallace and Hobbs, 2006). The 850 to $500 \mathrm{hPa}$ thickness is a function of the average temperature and the average moisture content of the air through the specific layer, which are two properties associated with the virtual temperature. Therefore, the specific thickness (between level $z_{1}$ (with pressure $p_{1}$ ) and level $z_{2}$ (with pressure $\left.p_{2}\right)$ ) is associated with virtual temperature $\left(T_{\mathrm{v}}\right)$, as shown below:

$z_{2}-z_{1}=-\frac{R_{\mathrm{d}} \overline{T_{\mathrm{v}}}}{g} \cdot \ln \left(\frac{p_{2}}{p_{1}}\right)$.

The virtual temperature is used for estimating the available convective potential energy and its exclusion may lead to relatively important errors (Doswell and Rasmussen, 1994).
CAPE $=\int_{z_{\mathrm{EL}}}^{z_{\mathrm{LFC}}} g \cdot\left(\frac{T_{\mathrm{v}, \text { parcel }}-T_{\mathrm{v}, \text { env }}}{T_{\mathrm{v}, \text { env }}}\right) \mathrm{d} z$,

where $z_{\mathrm{LFC}}$ and $z_{\mathrm{EL}}$ are the heights of the levels of free convection and equilibrium, respectively, $T_{\mathrm{v}, \text { parcel }}$ is the virtual temperature of the specific parcel, $T_{\mathrm{v}, \text { env }}$ is the virtual temperature of the environment, and $g$ is the acceleration due to gravity.

Consequently, the 850 to $500 \mathrm{hPa}$ thickness effect on CAPE led us to include this indicator in the LII formation. For practical reasons, the thickness seasonality was subtracted using the moving average. It has been demonstrated that it should be less than 0 for the period from May to August and less than 40 for September and October. The ACAPE and the thickness term are represented schematically in Figs. 2 and 3.

Thus, the Energy Term (ET) is the conjunction of ACAPE and thickness term, in other words

$\mathrm{ET}=\mathrm{ACAPE} \wedge$ Thickness Term.

\subsection{Moisture term}

According to previous studies (Humphreys, 1926; Showalter and Fulks, 1943; Fawbush et al., 1951; Appleby, 1954; Whitney and Miller, 1956; Miller, 1967; Schaefer, 1986) low-level moisture is a prerequisite for thunderstorm initiation and development. Usually, low-level moisture increases instability as more latent heat is available to the lower atmosphere. On the contrary, when mid-level moisture increases, the atmospheric instability can decrease because moist air is less dense and therefore less able to evaporate precipitation than the drier air. The evaporation of precipitation at or beneath cloud level causes air-cooling inside precipitation downdrafts, making the air denser and increasing instability, although the amount of precipitation is usually small.

The minimum amount of moisture that was noticed in the recorded events, expressed in relative humidity terms, was $60 \%$ at $850 \mathrm{hPA}, 40 \%$ at $700 \mathrm{hPA}$ and $120 \%$ for their sum (see Fig. 4). The aforementioned thresholds are insufficient for heavy rainfall. Although increasing moisture increases the potentiality for heavy rainfall within the thunderstorm, the moisture in the upper levels may decrease the instability (Bol, 2006). This is not taken into account, although it was found that the values of the upper levels were associated with the thunderstorms.

\subsection{Terrain heating effect and local features}

A lifting force is necessary for a rising parcel of air to overcome the convective inhibition, which occurs when a layer of warmer air is above a particular region of cooler air, hindering the latter from ascending into the atmosphere (Mapes, 2000). Thus, a temperature inversion is created and therefore a stable region of air. The lift mechanism pushes the cooler 


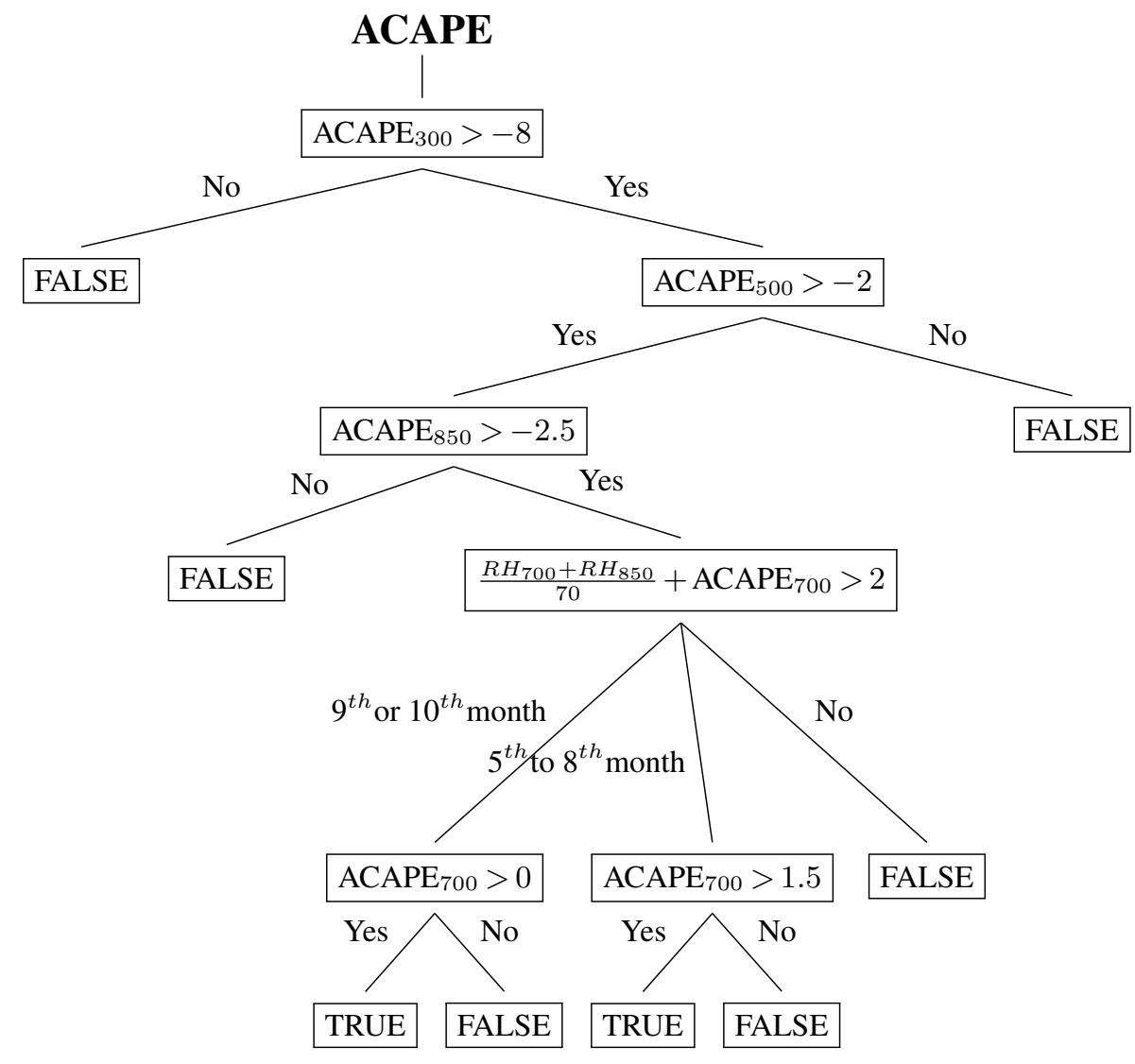

Figure 2. Schematic diagram of ACAPE.

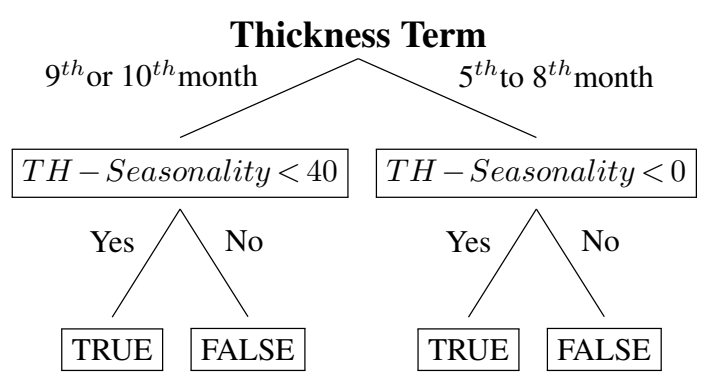

Figure 3. Schematic diagram of the thickness term.

parcel of air over the inversion, contributing to the thunderstorm development. The main sources of a lift mechanism are associated with terrain features, heating and sea breeze.

\subsubsection{Terrain heating effect term}

A cold air mass can be heated from the ground, increasing its instability and vice versa. If an air mass is cooled from the terrain, it becomes denser and unfavorable for thunderstorm development (Kessler, 1983). Taking into account the terrain thermal conductivity with respect to heat storage (terrain heat capacity) the terrain heating effect is suggested to be modeled as

$\mathrm{TH}=T_{0}-\frac{2 T_{-1}+T_{-2}}{3}$,

where $T_{0}$ is the temperature of the terrain on a specific day, $T_{-1}$ is the temperature 1 day prior to $T_{0}$, and $T_{-2}$ is the temperature 2 days prior to $T_{0}$; all temperatures are measured at the same time. The weight factor for $T_{-1}$ is set to 2 and for $T_{-2}$ it is set to 1 . They decrease as the effect decreases with time.

The threshold was estimated at $\mathrm{TH}=2$, since greater values mean reduced instability. In the cases where the current is southwesterly, and is consequently supplying the area, the factor $\mathrm{TH}$ becomes more ineffective moisture, and this can be modeled by subtracting 3 degrees (see Fig. 5).

\subsubsection{Locality term}

Apart from the local influences that were modeled within the aforementioned terms, the dissolving effect of the easterly downdraft current due to the high mountains on the eastern part of the area were also examined (see Fig. 6). 


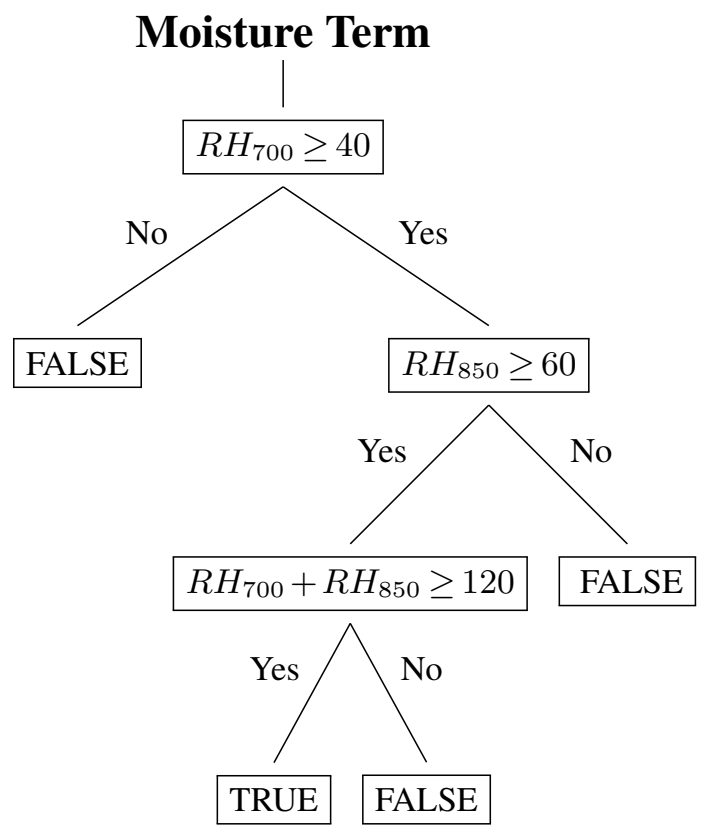

Figure 4. Schematic diagram of the moisture term.

\section{Terrain Heating Effect Term}

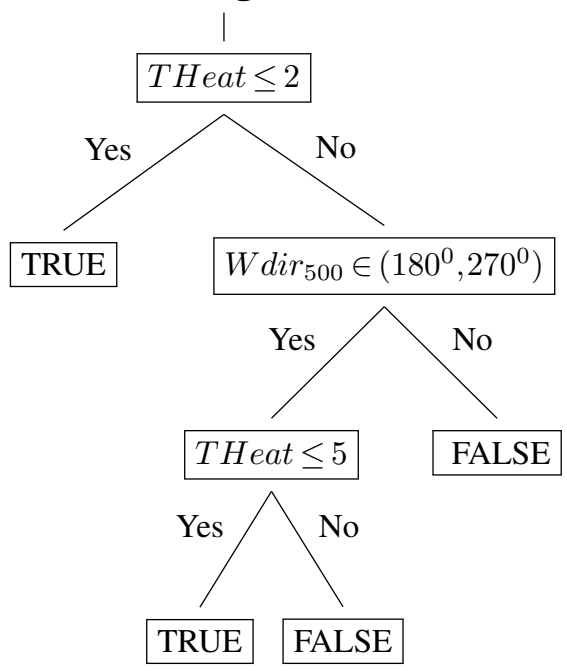

Figure 5. Schematic diagram of the terrain heating effect term.

\subsection{The Local Instability Index (LII)}

Summarizing the above terms, the LII can be considered as the conjunction of the ET (energy term), MT (moisture term), THET (terrain heating effect term) and LT (locality term):

$\mathrm{LII}=\mathrm{ET} \wedge \mathrm{MT} \wedge \mathrm{THET} \wedge \mathrm{LT}$.
Table 1. LII: consistency table for the period 1 May 2006 to 31 Ocbober 2007.

\begin{tabular}{lll}
\hline & & Observation \\
\hline LII & 54 (correct result) & 34 (unexpected result) \\
& 0 (missing result) & 1418 (correct absent of result) \\
\hline
\end{tabular}

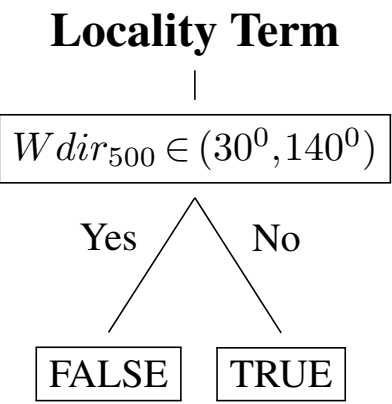

Figure 6. Schematic diagram of the locality term.

\section{Calculations, evaluation and discussion}

The LII was calculated on the basis of the data of the period 1 May 2006 to 31 October 2007. Overall, 88 severe thunderstorms events were predicted. It is important to note that the actual number was 54 and all of them were predicted. Although the importance of $100 \%$ recall is controversial, the risk of neglecting a severe thunderstorm warning may prove hazardous, since injuries or fatalities and damages to structures or to the environment may not be prevented. The LII predicted 1418 no thunderstorm events and the actual number was 1452 .

The consistency table of LII for the specific period is shown in the Table 1 and its performance is described as follows:

- Precision (the number of thunderstorms that occurred from those that had been forecasted/the number of the latter) $=61 \%$

- Recall (the number of thunderstorms that were forecasted from those that occurred/the number of the latter) $=100 \%$

- Fall-out (the number of cases with no thunderstorms from those that had not been forecasted/the number of the latter) $=98 \%$.

The weighted harmonic mean of precision and recall, the traditional $F$ measure or balanced $F$ score is

$F=2 \cdot \frac{\text { Precision } \cdot \text { Recall }}{\text { Precision }+ \text { Recall }}$

resulting in $F=76 \%$ and the preferable by HNMS (Petrou et al., 2009) norm for measuring the effectiveness of Indices in case of severe phenomena, the $F_{1.2}$-measure which puts 
Table 2. LII: consistency table for the period 1 June 2008 to 30 June 2011.

\begin{tabular}{lll}
\hline \multicolumn{2}{c}{ Observation } \\
\hline LII & 89 (correct result) & 74 (unexpected result) \\
& 0 (missing result) & 2165 (correct non-event) \\
\hline
\end{tabular}

more emphasis on recall than on precision (1.2 times more) is

$F_{1.2}=\left(1+1.2^{2}\right) \cdot \frac{\text { Precision } \cdot \text { Recall }}{1.2^{2} \text { Precision }+ \text { Recall }}$,

resulting in $F_{1.2}=79 \%$ (total performance).

The LII was then calculated for the second period, 1 June 2008 to 30 June 2011. A total of 163 severe thunderstorms were predicted. During this period the actual number was 89 and LII predicted all of them. The LII predicted 2165 no thunderstorm events and the actual number was 2239 . The consistency table of the LII for the specific period is shown in Table 2 and its performance is Precision $=55 \%$, Recall $=100 \%$, and Fall-out $=97 \%$. The balanced $F$ score is $F=71 \%$ and the weighted $F$ score, i.e. the total performance, is $F_{1.2}=75 \%$. The performance of LII per month is illustrated in Table 3.

It is demonstrated that the LII performed very well for the months May, June, September and October, when unstable weather conditions are more likely to occur. In these cases, most of the thunderstorm events took place during noon or afternoon when the terrain heating effect is stronger. The lower levels of the atmosphere were moist enough and the CAPE was suitable. During July and August of the specific period, only two thunderstorms with heavy rainfall events occurred. This was expected, as the atmosphere in the region is generally stable for these months, as was previously explained. Although the performance of LII for July and August is rather low, its use is still beneficial, taking into account the severity of the events and that the recall of the LII is $100 \%$.

\section{Conclusions}

This study presents an alternative methodological tool for the prediction of severe thunderstorms occurring over a specific area. Northwestern Peloponnese was chosen to illustrate the proposed tool, because many thunderstorms with heavy rainfall have occurred there with disastrous impacts.

The parameters used were constrained to those that are easily available to operational forecasters while performing their everyday duties. The statistical correlations of the parameters with the observations were examined. In the cases where correlations were not justified by the relative theory, the respective parameters were neglected. Then, the Local Instability Index (LII) was inferentially drawn by using them.
Table 3. LII: monthly performance for the period 1 June 2008 to 30 June 2011.

\begin{tabular}{lrrcccc}
\hline & LII & Actual & Precision & Recall & $F$ & $F_{1.2}$ \\
\hline May & 17 & 6 & 0.35 & 1.00 & 0.52 & 0.57 \\
June & 23 & 7 & 0.30 & 1.00 & 0.47 & 0.52 \\
July & 10 & $\mathbf{1}$ & 0,10 & 1.00 & 0.18 & $\mathbf{0 . 2 1}$ \\
August & 11 & $\mathbf{1}$ & 0.09 & 1.00 & 0.17 & $\mathbf{0 . 2 0}$ \\
September & 51 & 34 & 0.67 & 1.00 & 0.80 & 0.83 \\
October & 51 & 40 & 0.78 & 1.00 & 0.88 & 0.90 \\
\hline
\end{tabular}

The LII is a threshold function that consists of the low-level moisture, a practical approximation of the CAPE, the terrain heating effect and a formalized operational experience. It was found that the LII has satisfactory total performance (75\%) over the northwestern Peloponnese region for the period from 1 June 2008 to 30 June 2011, predicting all the thunderstorms with heavy rainfall events (recall $=100 \%$ ).

The future challenge for further development and optimization of this tool is to experiment with the LII for a longer period and for hydrological basins all around Greece since in case of good performance, the LII would be at the disposal of operational forecasters of HNMC.

Acknowledgements. We would like to thank the HNMC operational forecasters for their help.

Edited by: P. Nastos

Reviewed by: M. V. S. Sioutas and another anonymous referee

\section{References}

Acock, M. C. and Pachepsky, Ya. A.: Estimating Missing Weather Data for Agricultural Simulations Using Group Method of Data Handling, J. Appl. Meteorol. Clim., 9, 1176-1184, 2000.

Aebischer, U. and Schär, C.: Low-Level Potential Vorticity and Cyclogenesis to the Lee of the Alps, J. Atmos. Sci., 55, 186-207, doi:10.1175/1520-0469(1998)055<0186:LLPVAC>2.0.CO;2, 1998.

Appleby, J. F.: Trajectory method of making short-range forecasts of differential temperature advection, instability, and moisture, Mon. Weather Rev., 82, 320-334, 1954.

ARMADA Data Mining Tool version 1.4, available at: http://www.mathworks.com/matlabcentral/fileexchange/

3016-armada-data-mining-tool-version-1-4, last access: 15 May 2014, updated: 18 February 2011.

Beyer, K., Goldstein, J., Ramakrishnan, R., and Shaft, U.: When Is "Nearest Neighbor" Meaningful?, in: Int. Conf. on Database Theory, London, UK, 217-235, 1999.

Brody, L. R. and Nestor, M. J. R.: Regional Forecasting Aids for the Mediterranean Basin, Handbook for Forecasters in the Mediterranean, Part 2, Naval Research Laboratory, Monterey, USA, 1980. 
Bol, A.: Buoyancy and CAPE, Principles of Convection, University Corporation for Atmospheric Research, http://meted.ucar. edu/mesoprim/cape/print.htm (retrieved: 26 August 2012), 2006.

Boyden, C. J.: A Simple Instability Index for Use as a synoptic parameter, Met. Meg., USA, 198-210, 1963.

Branick, M.: A Comprehensive Glossary of Weather Terms for Storm Spotters, NOAA Technical Memorandum NWS SR-145, NOAA, Fort Worth, Texas, 1993.

Chrysoulakis, N., Spiliotopoulos, M., Domenikiotis, C., and Dalezios, N. R.: Towards Monitoring of Regional Atmospheric Instability Through MODIS/AQUA Images, International Symposium "GIS and Remote Sensing: Environmental Applications", 7-9 November 2003, Volos, 155-166, 2006.

Curry, J. A. and Webster, P. J.: Thermodynamics of Atmospheres and Oceans, Vol. 65, International Geophysics, Academic Press, London, UK, 1999.

Dalezios, N. R. and Papamanolis, N. K.: Objective assessment of instability indices for operational hail forecasting in Greece, Meteorol. Atmos. Phys., 45, 87-100, 1991.

Dimitrovaa, T., Mitzevab, R., and Savtchenko, A.: Environmental conditions responsible for the type of precipitation in summer convective storms over Bulgaria, Atmos. Res., 93, 30-38, 2009.

Doswell III, C. A. and Rasmussen, E. N.: The effect of neglecting the Virtual Temperature Correction on CAPE Calculations, Weather Forecast., 9, 625-629, 1994.

Fawbush, E. J., Miller, R. C., and Starrett, L. G.: An empirical method for forecasting tornado development, B. Am. Meteorol. Soc., 32, 1-9, 1951.

George, J. J.: Weather Forecasting for Aeronautics, Q. J. Roy. Meteorol. Soc., 87, 120, doi:10.1002/qj.49708737120, 1960.

Graham, I., Ronald Shaw, R., Dixon, D., and Paul Jones III, J.: Research Methods in Geography, in: Chapter: Theorizing Our World, edited by: Gomez, B. and Paul Jones III, J., Blackwell Publishing Ltd, Sussex, UK, 2010.

Haklander, A. J. and Van Delden, A.: Thunderstorm predictors and their forecast skill for the Netherlands, Atmos. Res., 67-68, 273299, 2003.

Holton, J. R.: An Introduction to Dynamic Meteorology, 4th Edn., Academic Press, Seattle, Washington, 2004.

Hoskins, B. J.: On the existence and strength of the summer subtropical anticyclones - Bernhard Haurwitz memorial lecture, B. Am. Meteorol. Soc., 77, 1287-1292, 1996.

Humphreys, W. J.: The tornado, Mon. Weather Rev., 54, 501-503, 1926.

Jacovides, C. P. and Yonetani, T.: An evaluation of stability indices for thunderstorm prediction in Greater Cyprus, Weather Forecast., 5, 559-569, 1990.

Jefferson, G. J.: A modified instability index, Meteorol. Mag., 92, 92-96, 1963a.

Jefferson, G. J.: A further development of the instability index, Meteorol. Mag., 92, 313-316, 1963 b.

Keeley, S. and Källén, E.: Operational and research activities at ECMWF now and in the future, ECMWF, available at: old. ecmwf.int/newsevents/training/meteorological_presentations/ 2013/PR2013/Keeley/ECMWF-Past-FuturePR_final.pdf (last access: 15 May 2014), 2013.

Kessler, E.: Thunderstorm Morphology and Dynamics, University of Oklahoma Press, USA, 1983.
Kljun, N., Sprenger, M., and Schär, C.: Frontal modification and lee cyclogenesis in the Alps: A case study using the ALPEX reanalysis data set, Meteorol. Atmos. Phys., 78, 89-105, doi:10.1007/s007030170008, 2000.

Lakatos, I.: Proofs and Refutations, The British Journal for the Philosophy of Science, 14, pp. 1-25, 129-139, 221-243, 296, 342 , Oxford Journals, Oxford, UK, 1963.

Litynska, Z., Parfiniewicz, J., and Pinkowski, H.: The prediction of air mass thunderstorms and hails, No. 450, WMO, Warsaw, Poland, 128-130, 1976.

Maheras, P. and Anagnostopoulou, C.: Circulation Types and their Influence on the Interannual variability and precipitation changes in Greece, in: Mediterranean Climate - Variability and Trends, Springer Verlag, Berlin, Heidelberg, 215-239, 2003.

Mapes, B. E.: Convective Inhibition, Subgrid-Scale Triggering Energy, and Stratiform Instability in a Toy Tropical Wave Mode, J. Atmos. Sci., 57, 1515-1535, 2000.

Marinaki, A., Spiliotopoulos, M., and Michalopoulou, H.: Evaluation of atmospheric instability indices in Greece, Adv. Geosci. 7, 131-135, doi:10.5194/adgeo-7-131-2006, 2006.

MEECC - Ministry of Environment, Energy and Climate Change: Synoptic Description of the Hydrological Basin of Northern Peloponnese, available at: http://wfd.opengov.gr/index.php? option=com_content\&task=view\&id=25\&Itemid=12, last access: 15 June 2012.

Metaxas, D. A., Philandras, C. M., Nastos, P. T., and Repapis, C. C.: Variability of precipitation pattern in Greece during the year, Fresen. Environ. Bull., 8, 1-6, 1999.

Michalopoulou, H. and Jacovides, C. P.: Instability indices for the Cyprus area, Meteorol. Atmos. Phys., 37, 153-157, 1987.

Michalopoulou, H. and Karadana, E.: A review of instability indices for the greater area of Athens, 3rd Hellenic Conference on Meteorology and Atmospheric Physics, Athens, Greece, 193-198, 1996.

Miller, R. C.: Notes on the analysis and severe storm forecasting procedures of teh Military Weather Warning Center, Tech. Report 200, AWS, USAF, Headquarters, AWS, Scott AFB, Illinois, 1967.

Moncrieff, M. W. and Miller, M. J.: The dynamics and simulation of tropical cumulonimbus and squall lines, Q. J. Roy. Meteorol. Soc., 102, 373-394, 1976.

Nemhauser, G. L. and Wolsey, L. A.: Integer and Combinatorial Optimization, John Wiley \& Sons, Canada, 1988.

Peppler, P. A.: A Review of Static Stability Indices and related Thermodynamic Parameters, Illinois State Water Survey Division, SWS Miscellaneous Publication 104, Illinois, USA, 1988.

Peppler, R. A. and Lamb, P. J.: Tropospheric static stability and central North American growing season rainfall, Mon. Weather Rev., 117, 1156-1180, 1989.

Petrou, C., Mavroudakis, T., and Giannopoulos, P.: Verification of Extreme Weather Phenomena in HELLAS, Vol. 14, The European Forecaster Newsletter of WGCEF, Météo-France, Trappes, France, 22-23, 2009.

Prezerakos, N. G.: An investigation into the conditions in which airmass thunderstorms occur at Athens, Meteorol. Mag., 118, 3136, 1989.

Reuter, G. W. and Aktary, N.: A slantwise Showalter index based on moist symmetric instability: Results for Central Alberta, Atmosphere-Ocean, 31, 379-394, 1993. 
Rodwell, M. J. and Hoskins, B. J.: Subtropical Anticyclones and Summer Monsoons, J. Climate, 14, 3192-3211, 2001.

Schaefer, J. T.: Severe thunderstorm forecasting: A historical perspective, Weather Forecast., 1, 164-189, 1986.

Showalter, A. K.: A Stability Index for Thunderstorms Forecasting, B. Am. Meteorol. Soc., 34, 250-252, 1953.

Showalter, A. K. and Fulks, J. R.: Preliminary report on tornadoes, No. 806, US Dept. of Commerce, Weather Bureau, Washington, USA, 162 pp., 1943.

Sioutas, M. V. and Flocas, H. A.: Hailstorms in Northern Greece: synoptic patterns and thermodynamic environment, Theor. Appl. Climatol., 75, 189-202, 2003.

Tian, B. and Fan, K. : Factors favorable to frequent extreme precipitation in the upper Yangtze River Valley, Meteorol. Atmos. Phys., 121, 189-197, 2013.

Trigo, I. F., Bigg, G. R., and Davies, T. D.: Climatology of Cyclogenesis Mechanisms in the Mediterranean, Mon. Weather Rev., 130, 549-569, 2001.

Trochim, W.: The Research Methods Knowledge Base, 2nd Edn., Atomic Dog Publishing, Cincinnati, OH, 2000.
Tyagi, B., Krishna, V. N., and Satyanarayana, A. N. V.: Study of thermodynamic indices in forecasting pre-monsoon thunderstorms over Kolkata during STORM pilot phase 2006-2008, Nat. Hazards, 56, 681-698, 2011.

Veremei, N. E., Dovgalyuk, Yu. A., Efimov, S. V., Nosova, A. M., and Pechenkin, A. A.: Studying the showers and thunderstorms on the territory of Russia using the numerical model of convective cloud and the reanalysis data, Russian Meteorol. Hydrol., 38, 20-27, 2013.

Wallace, J. M. and Hobbs, P. V.: Atmospheric Science, 2nd Edn., Academic Press, Washington, USA, 2006.

Whitney, Jr., L. F. and Miller, J. E.: Destabilization by differential advection in the tornado situation 8 June 1953, B. Am. Meteorol. Soc., 37, 224-229, 1956.

Xoplaki, E.: Climate variability over the Mediterranean, Inauguraldissertation der Philosophisch-naturwissenschaftlichen Fakultät der Universität Bern, Bern, 2002.

Ziakopoulos, D.: Weather, The son of the earth and the sun (Forecast), Artio stamp Ltd, Athens, Greece, 2009.

Zverev, A. S.: Practical Work in Synoptic Meteorology, 1st Edn., Hydrometeorological Publishing House, Leningrad, Russia, 1972. 